\title{
Shepherd's Office. The Politics of Digital Labor and Its Impact on the Amazon Mechanical Turk Workers
}

\author{
ZANETA ZUKALOVA \\ Artist and co-founder of Shepherd's Office
}

\begin{abstract}
Shepherd's Office (SO) is a collaborative performance and research project between artists Daniela Vainio and Zaneta Zukalova, first introduced at Tate Modern (Tate Exchange) London in 2017, which questions the systematic order of Amazon Mechanical Turk. In May 2019, SO held a live investigative performance at the Art Fair Suomi in Helsinki, with an aim to collect the data that informs this article; SO's focus was on the socio-political background of Amazon Mechanical Turk Workers and their personal relations to and opinions on the platform. The present article introduces both the artistic and investigative aspects of the project and the problematics of Amazon Mechanical Turk, and offers an insight into the research inputs, processes, and outcomes.
\end{abstract}

"I feel like fucking shit, I feel this way most days though. But in particular I really feel it today because fuck life and all the bullshit we have to conform to and the constructs of this awful society. ... I have had a better life than majority of the people in this city but thats relative to the social ladder we have in this world. ... I think generally I am stressed out of my fucking mind that it seriously causes other health issues for me. Im at a point in life where I just dont give a fuck anymore, ive become jaded because of the harsh reality of how shitty others can be and the way this 'matrix' system works."

- Worker 39

"I was looking for remote work that I could slot in at odd hours of the day. I think I have stayed mainly out of force of habit and bloody-mindedness, waiting for their remuneration policies to improve. I hate myself for contributing to this type of economy. ... I have received no financial benefits yet, other than accruing a balance on the Amazon US site-but often my desperation makes it seem better to earn virtually nothing doing repetitive online tasks than actually earning nothing."

- Worker 127 


\section{INTRODUCTION}

The Amazon Mechanical Turk (AMT), inspired by Jeffrey Bezos' idea and coined in 2001 by Vonky Harinarayan, is described as a crowdsourcing online platform, where employers (Requesters) register their HITs (Human Intelligence Tasks) to be completed by Workers, for pay. HITs are simple assignments which at the moment cannot be completed by computers, or which are more effectively completed by human rather than machine labor, such as identifying information, predominantly in text format, seen in an image. Other common tasks are transcribing audio clips, reviewing documents and websites, ${ }^{1}$ machine learning development, ${ }^{2}$ or generating opinions on particular subjects. For many businesses, NGOs, and academics, the HITs system is considered an easy, fast, and inexpensive way of conducting surveys and experiments and collecting other data from a global and stable pool of workers. ${ }^{3}$

Despite presenting significant advantages for conducting experiments and collecting data, such as its low-cost and short turnaround characteristics, and although it claims to widen work opportunities to areas of scarcity, ${ }^{4}$ being understood as part of a digital labor market, it presents several questions and paradoxes, especially on the Workers' side. There is a trail of evidence that AMT manifests an unethical approach to rewarding labor and, among similar platforms such as Figure Eight, Microworkers, and Clickworker, to the labor market itself. It is argued that the design of such market platforms systematically privileges the Requesters over the Workers, ${ }^{5}$ resulting in issues such as unsatisfactory rewards versus effort, no reward for time "in between" completing HITs, HITs rejections, discrimination based on the country of residence on the Workers' side, and loopholes that allow Requesters to easily abdicate the responsibility of paying Workers. With an increasing transition of labor from physical to digital environments and of contracted regulated work to freelance microtasking, completing HITs is the only option due to lack of work opportunities for many people all around the world. ${ }^{6}$

Shepherd's Office (SO) combines the means of research with performance and installation art to effectively navigate an investigation within the AMT platform. This combination allows the investigation process, progress as well as outcome, to be presented immediately to the public, as well as being stored for future reference and exposure. $S O$ views its role as an information mediator and presenter, and, among other art projects such as Workers' Forum (2015) by Pilvi Takala, SerfNet (2014) by Angela Washko and Alex Young, and Aaron Koblin's The Sheep Market (2006), serves as a vital contribution to the contemporary discourse on microtasking and crowdworking. These projects are considered in the discussion that follows. As part of the investigation, the Workers were asked for examples of their dependence on AMT as a source of income, their hourly wage on AMT, the reasons to join AMT, and whether these factors are linked to the political or economic situation of their country/area. They were also asked to describe their feelings while completing HITs, as an indicator of satisfaction with their employment situation and HITs themselves. These topics will be introduced and discussed in this article. 


\section{SHEPHERD'S OFFICE}

Shepherd's Office (SO) functions as a fictional company with two employees, Jeffrey and Venky Shepherd, registered at Amazon Mechanical Turk as a Requester. To briefly outline its roots, $S O$ arises from the "Ubernism" initiative debuting at Tate Modern (Tate Exchange), London in 2017, supervised by Bernd Behr, artist and lecturer at Camberwell College of Arts, UAL. At Tate Modern, $S O$ registered only one HIT, in which the Workers had the right to conjure up and direct tasks to $S O$, thereby reversing the standardized order of power dynamics in an employment relationship. The Workers were asked to assign $S O$ any task to perform around Tate Modern; its outcome in the form of recordings and pictures can be found at @shepherdsoffice Instagram account.

During the performance at Art Fair Suomi in Helsinki, which lasted for 36 hours in total, $S O$ assigned a range of HITs to Workers. The subjects were not informed about the experimental component of the task; the HITs were posted as any other HITs on AMT, with task title "Creative Task" or "Survey" and keywords "chat, text, writing, survey, short survey." In this way, $S O$ was able to communicate with the Workers, ask questions on particular topics, collect their responses and present them immediately to the public - in both textual and visual (graphs, pie charts) form. These responses were attached to the wall and refreshed every now and then, once the wall was fully covered. Data gained throughout the performance were processed into statistics and graphs, serving as a partial source for informing this paper. In a similar manner, Angela Washko and Alex Young's multi-media installation SerfNet (2014) incorporates both a selection of Workers' answers, and their renderings into graphs and charts. ${ }^{7}$ However, $S O$ combines the aspects of research and installation with the one of performance, opening a potential for diverse applications. Because of its "live" character, the research immediately dictates the shape of both performance and installation, which unfold, evolve, and do not repeat.

For its performance at Art Fair Suomi, Shepherd's Office (SO), as an officially registered company on AMT, set up an office that was open to the public. To maintain the flow and synchronisation of the research and the performance - SO's actions with the projection and the wall —and to preserve the stereotypical office ethos of maximizing productivity and minimizing distraction, the amount of contact in between $S O$ and the public had to be restricted. At the same time, one of the main pillars of the performance was to present the topic of digital labor and the research process itself in a cohesive manner. Assuming that most of the art fair visitors were not familiar with the performance subject matter, a form of communication with the public had to be present to some extent. $S O$ decided to implement an office phone in both of its performative and installation aspects. In this way, $S O$ was able to provide information about the performance, Amazon Mechanical Turk, and its Workers in a controllable and manageable way. To ensure that the project was accessible to its audience, it was also useful to incorporate a display of some contextual material alongside the Workers' responses on the wall, and a live projection of creating HITs and receiving them completed. 


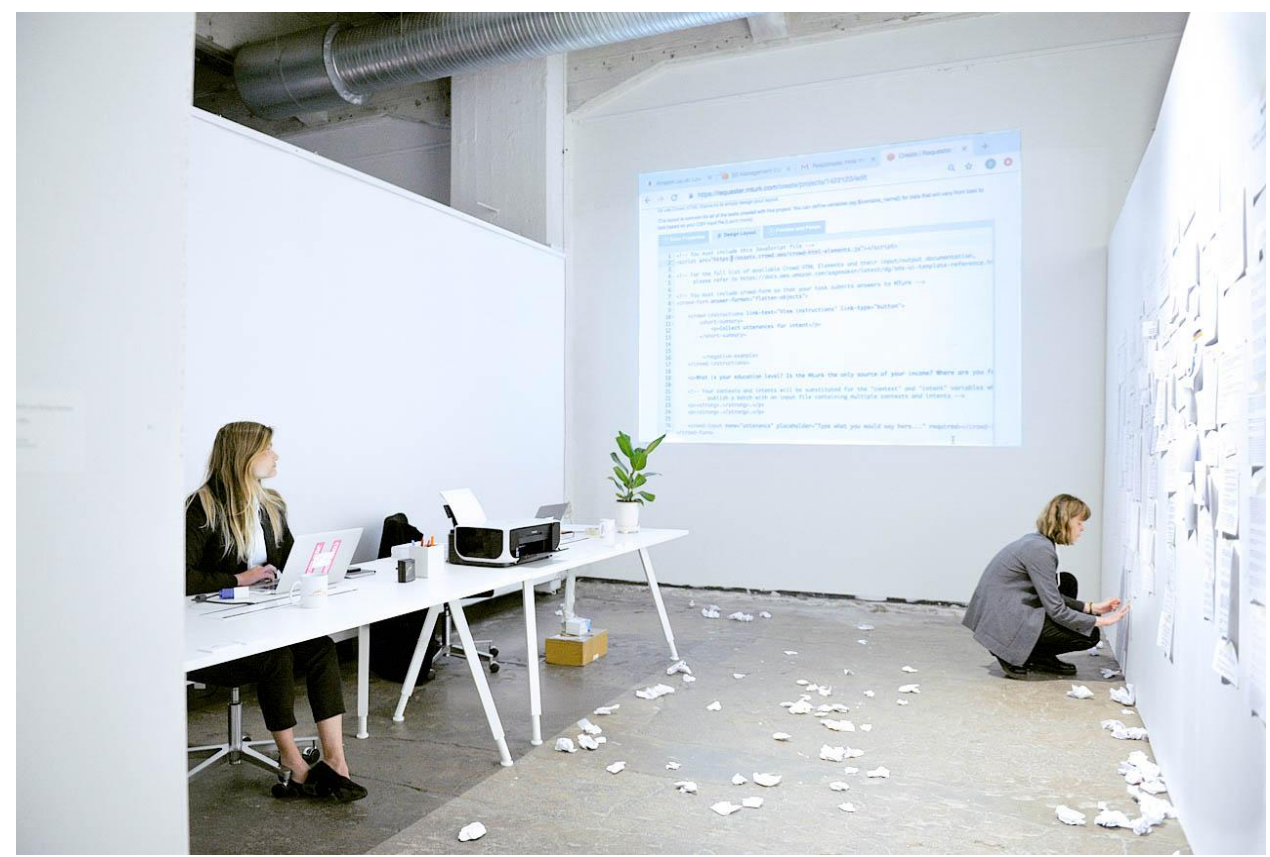

Figure 1. Shepherd's Office at Art Fair Suomi, 2019, photograph by Mark Stubbs

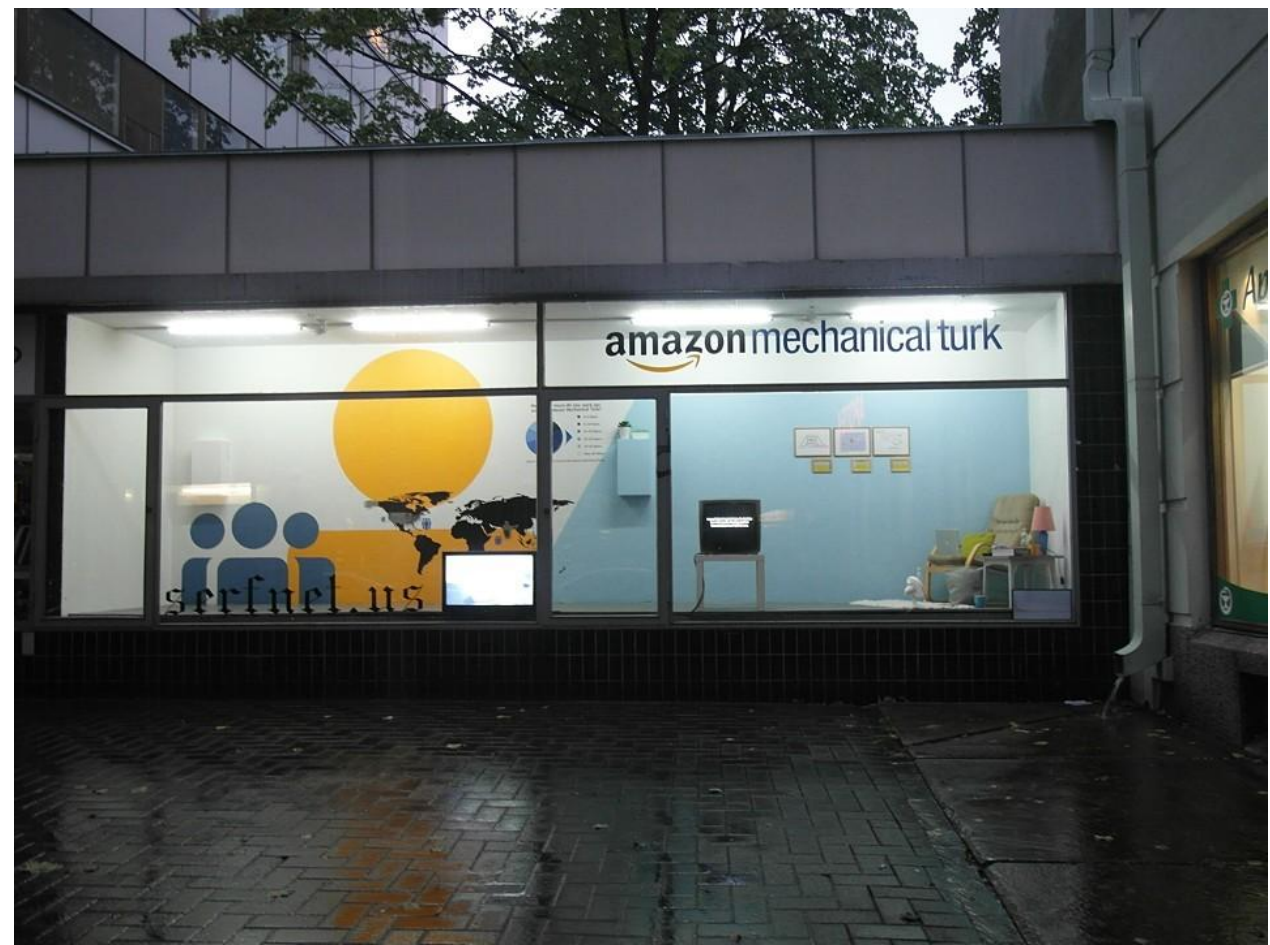

Figure 2. Angela Washko and Alex Young, SerfNet Installation View, 2014, courtesy of the artists 


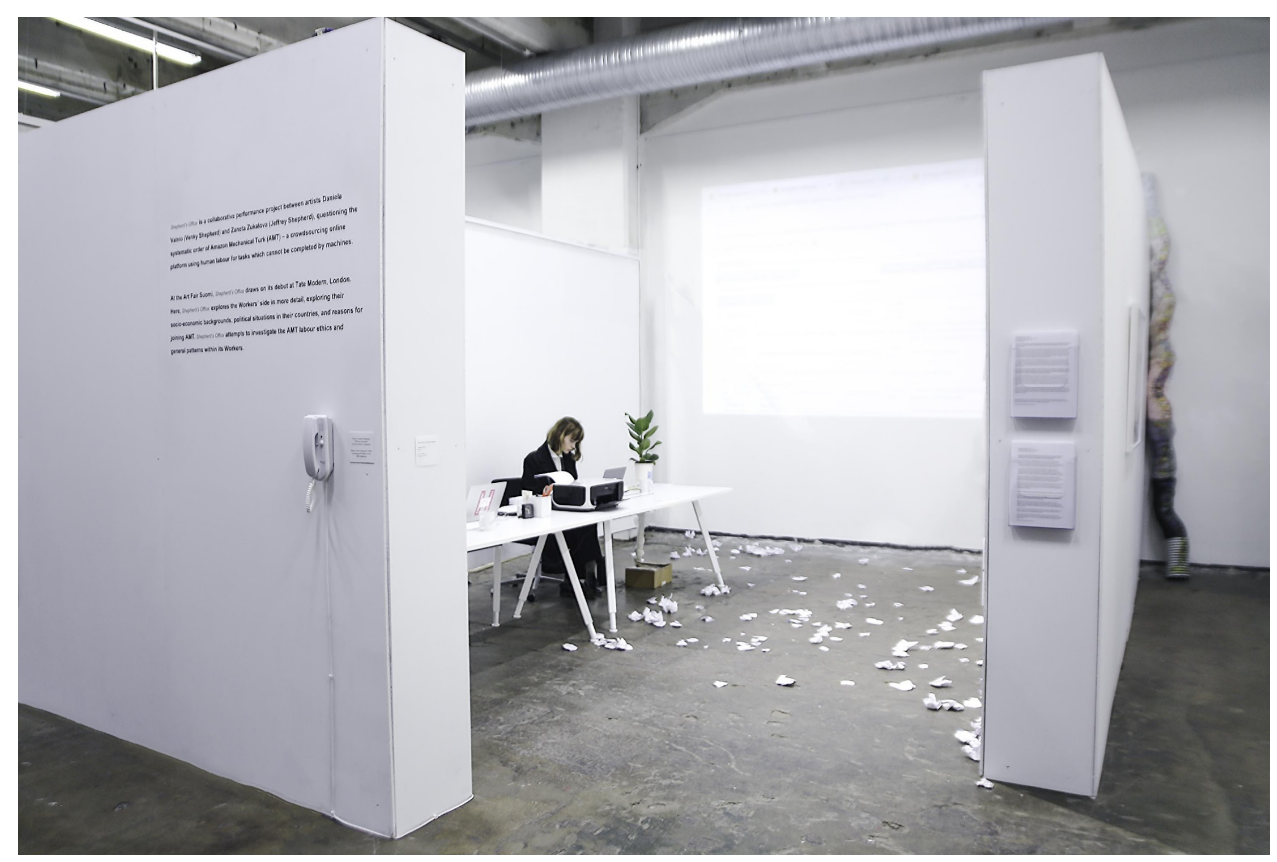

Figure 3. Shepherd's Office at Art Fair Suomi, 2019, courtesy of the artists

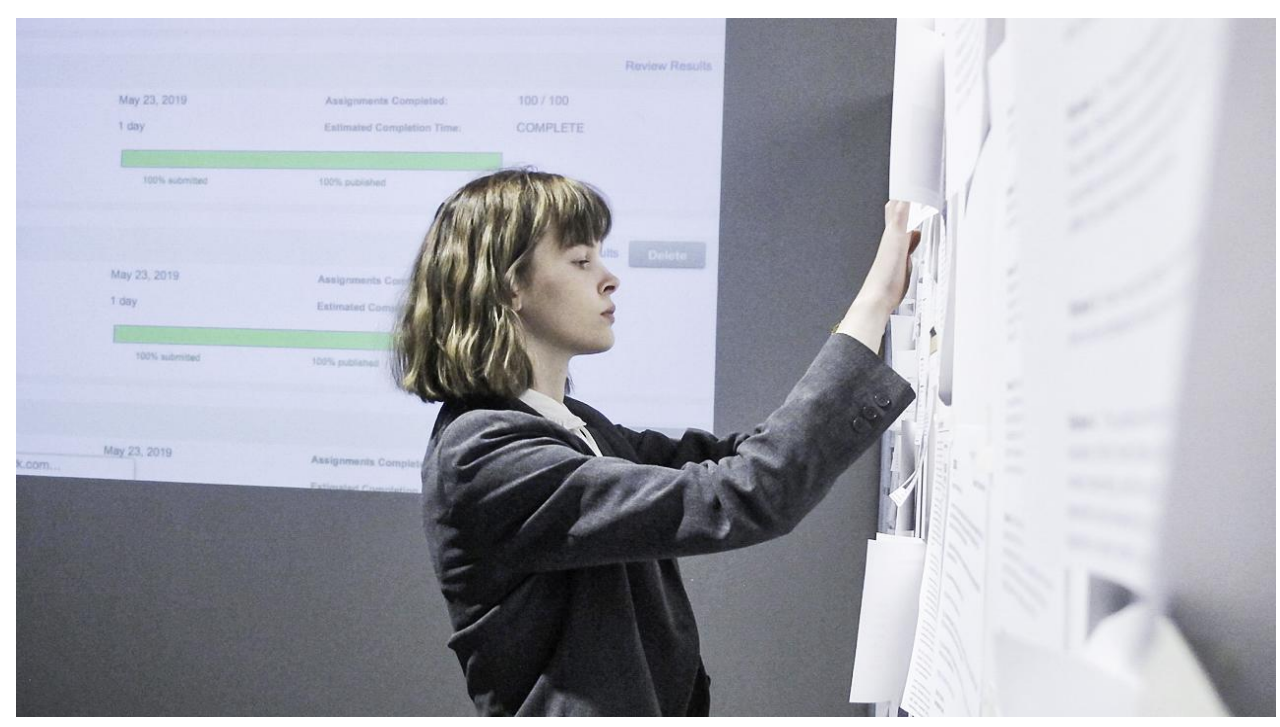

Figure 4. Shepherd's Office at Art Fair Suomi, 2019, photograph by Mark Stubbs 


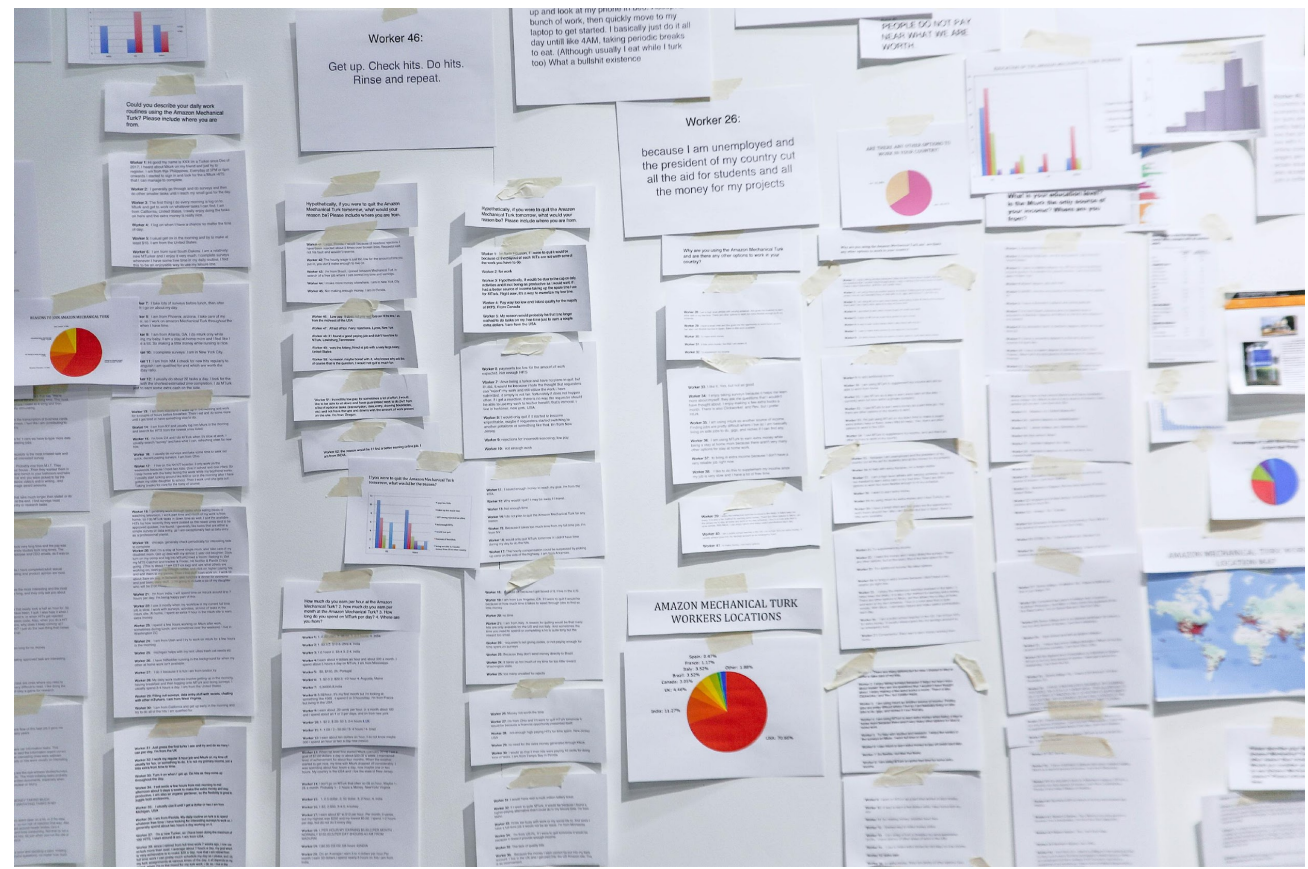

\section{Figure 4. Wall with responses from AMT Workers, 2019, courtesy of the artists}

In both name and subject matter, $S O$ exists in close proximity to The Sheep Market (2006) by Aaron Koblin. Only one HIT was registered, which asked the Workers to "draw a sheep facing to the left" for a reward of 2 cents, attempting to show a humanity behind a creative task executed by remote, anonymous, and therefore dehumanized Workers. The symbolism of the sheep and shepherd is relevant to The Sheep Market as well as the namesake of Shepherd's Office. Sheep were one of the first domesticated and the first ever cloned animals, and are a symbol for followers. ${ }^{9}$ Furthermore, in the Bible, heroic figures are often referred to as "Shepherds"; Abraham, for example, was a sheep keeper. ${ }^{10}$ Another connection to SO's name emerged with the discovery of an unaffiliated, identically named organisation, The Shepherd's Office, aimed at welcoming those rejected by society for reasons such as "social status, a criminal record, mistakes, misunderstandings, physical appearance, etc." with "encouragement through Bible study and just plain, simple fellowship."11 The implications of the name similarity and its connotations are purposely left open to readers' interpretations.

At Art Fair Suomi, $S O$ extended their field of focus beyond the exchange of power within a digital employment relationship, asking the Workers questions related for example to their political and economic background and satisfaction with Amazon Mechanical Turk itself. This probably touched on sensitive issues on the AMT side, as the $S O$ account, after only four hours of performance and actively posting HITs, was suspended. Despite posing a complication to the event, $S O$ saw the account removal as a measure of success, as it suggests an objection and vulnerability to certain investigations. The reasons for the suspension outlined by Amazon, shown in the figure below, 
were mendacious. $S O$ did not attempt to collect any personally identifiable information from the Workers' side and the account was suspended without any previous warning.

\author{
amazon \\ Your Account \\ Amazon.com

\section{Message From Customer Service} \\ Greetings from Amazon Mechanical Turk, \\ We regret to inform you that your Amazon Mechanical Turk (MTurk) account has been \\ suspended. We took this action because, despite previous warning, you continued to violate \\ the MTurk Acceptable Use Policy. Specifically, your account was closed for the following \\ violations: \\ -- Collecting personally identifiable information, or otherwise attempting to derive any \\ personally identifiable information about Workers \\ You can review the complete Acceptable Use Policy here: \\ https://www.mturk.com/acceptable-use-policy. \\ Your remaining prepaid HITs balance will be refunded to the payment method you used to \\ purchase the Prepaid HITs once your outstanding Worker liability has been resolved. \\ If you have questions, or if you believe this decision was made in error, you may email us using \\ the Contact Us form on our Requester website:
}

https://requester.mturk.com/contactus

Best regards,

Amazon.com

Figure 5. E-mail from Amazon Mechanical Turk, courtesy of the artists

\title{
THE PROBLEMATICS OF AMAZON MECHANICAL TURK WORKERS
}

Parallel to economic globalization, the market for outsourced digital work is expanding, meaning that workers from anywhere can complete work for hirers from anywhere. The digital labor market is alleged to fill in the gaps in areas with high unemployment rates, and to increase the income of individuals living in poor countries. According to Mark Graham, Isis Hjorth, and Vili Lehdonvirta:

"In response to this confluence of a need for more jobs in places where they do not currently exist, and the spreading of digital connectivity across billions of the world's population, millions of people have turned to outsourced digitally mediated work as a way to transcend some of the constraints of their local labour markets." 12 
With the expansion of the digital labor market, more people are becoming dependent on microtasking as the source of their income, even though the median hourly wage in the case of AMT Workers is below the national minimum wage in most of the AMT Workers' countries. Furthermore, the preconditions here are that not all workers from everywhere can compete equally in this type of market, nor can they access the market on the same level. ${ }^{13}$ There are a number of circumstances defining certain groups of AMT Workers-mostly international Workers - as disadvantaged or even disregarded, as discussed below.

\section{AMAZON MECHANICAL TURK = HIGH EFFORT $x$ POOR REWARD $x$ NO RIGHTS}

Most of the tasks are simple and short, yet poorly paid. The reward for most of them is under 10 cents. Even though the average Requester pays more than $\$ 11 / \mathrm{hr}$, the average Worker's income is listed as $\$ 3.13 / \mathrm{hr}$. This rate accounts for completing HITs, but also looking and waiting for HITs and getting HITs rejected or having to return them, which is time that nobody pays them for. ${ }^{14}$ In our study, the Workers reported their average hourly wage as \$2.93 - even lower than generally stated. In contrast to 2015, AMT's charge on what Requesters pay the Workers per HIT is now double the amount (20\% plus another $20 \%$ for HITs with more than 10 assignments plus bonuses) that it was in 2015, which certainly does not incentivize them to provide higher rewards to their Workers. ${ }^{15}$ The assumption would be that Workers from anywhere (competing on a global digital labor market that theoretically does not distinguish countries of residence) have equal opportunities, access to HITs as well as relatively equal hourly wages on the platform. However, a comparison of hourly wages in two dominant countries of AMT Workers, India and the US, showed a significant disparity: the average US Worker earns $\$ 3.94 / \mathrm{hr}$, while the average Indian Worker earns only $\$ 1.42 / \mathrm{hr}$, as reported by the Workers themselves. Both numbers are below the national minimum wage, which is $\$ 7.25-13.25 / \mathrm{hr}$ in the $\mathrm{US}^{16}$ and $\$ 2.40-6.35 / \mathrm{hr}$ in India. ${ }^{17}$ It is therefore observed that the global digital labor market - at least in the structure of AMT-does not transcend the conventional inequities that have defined the global non-digital labor market, and is actually worse in this metric by falling below the respective countries' national minimum wage. The Workers' wages are affected by the availability of tasks, which in turn is influenced by a number of Requester-controlled factors-HITs can be set to be accessed only by Workers of certain geolocations or language demographics. This specifically accounts for the disparity observed in the wages of US Workers, which as Graham et al. (2017) suggest are higher because of "their embeddedness in local institutional structures." "In other words, a large number of HITs from US Requesters are specifically targeted at the American population, and international Workers are not eligible to complete them. Furthermore, a large proportion of Requesters are based in the US, amplifying the effect of disparity within the higher wages of US Workers. Even though our HIT was not aimed in this direction, when we asked the Workers what their reason would be for quitting at AMT, some pointed out a degree of discrimination based on the country of residence, as for example: 
"I am from Italy. A reason for quitting would be that many hits are only available for the US and not Italy."

"Being Indian I do not have much task to do."

The difference in hourly wages could also, at least to some extent, be explained by another AMT accessibility issue: workers from developing countries with a slower internet connection are significantly disadvantaged. To cite one example, the US average connection speed is $119.09 \mathrm{Mb} / \mathrm{s}$, while in India it is $29.06 \mathrm{Mb} / \mathrm{s}$ and in many African and South American countries around 3-4 Mb/s or lower, ${ }^{19}$ making the time needed to complete some HITs, especially those requiring action on remote websites, much greater. This further increases the chances that the HIT will expire, the Worker will not be not rewarded, and their approval rate will decrease.

According to several Workers, many HITs take much longer to complete than stated in their time frames, or inform the Workers that they are not qualified after minutes of completing them, or require them to create an account on external websites while the time for HIT submission runs out. Some Workers reported cases of malfunctioning or missing completion codes at the end of outsourced surveys, or HITs being rejected by the Requester even though the answer was correct, which were described as "stressful" or even "abusive." It is useful to note here that the design of AMT makes it incredibly easy for the Requesters to reject HITs but still keep the data, thereby not paying the Workers who completed them. Again, the Workers invested certain time and energy, yet there is no reward for their input in these instances. On the other hand, contracted, regular employment often provides compensation for having lunch and a cup of coffee, for example. Even though microtasking is the only source of income for nearly $30 \%$ of the Workers, and the main source of income for even more of them, they are still classified as "freelance contractors," or as Lilly Irani puts it, they are transformed into a "computational service," 20 dehumanized and alienated into a parallel dimension where employment contracts, benefits, and protections do not exist. This misclassification as "freelance contractors" or "taskers" applies not only to Amazon Mechanical Turk or crowdworking, but also to "work-on-demand via apps," such as Uber, Deliveroo, and other app-powered or online, demand-to-activity matching services. ${ }^{21}$ The overarching criticism is that these services try to avoid legal obligations associated with the status of employment, such as "compliance with minimum wage laws, social security contribution, anti-discrimination regulation, sick pay and holidays." 22 As the catchphrase "You don't work for us, you work with us" 23 from Ken Loach's 2019 movie Sorry We Missed You exemplifies, this disposal of rights begins in a feat of linguistic acrobatics that identifies platforms and crowdworkers not as employers and employees, but as collaborators. AMT is unambivalent in its positioning as observed in The Participation Agreement, describing itself in spartan terms as a "venue to conduct transactions,"24 shedding all responsibility towards monitoring of and involvement in any participants' matters or disputes. However, it does not end here; Workers' Forum (2015) by Pilvi Takala reveals that concerns reaching far beyond the role specification are often involved with microtasking. This 6 
min $23 \mathrm{sec}$ video offers a peek into an online group chat of Takala and her "colleagues,"other microtaskers, all working for a service providing its customers with simulated SMS partners. ${ }^{25}$ Even though their task is only to send "partner-like" messages, the conversations often diverge into reality and make them care for the customers, described as "emotional labor." ${ }^{26}$ Furthermore, Workers' Forum (2015) points out the lack of organization, information and training for the purpose of their role, shared with other gig economy jobs. It is not only "emotional labor," but also the running expenses associated with the necessary equipment are rarely reimbursed or accounted for within this type of labor. For instance, Uber drivers need to pay for their vehicle maintenance, insurance, and other associated expenses, ${ }^{27}$ and crowdworkers for internet access, electricity, etc. In other words, besides the prospects of work unprotected by labor laws, microtaskers often have to assume those responsibilities that would otherwise be taken care of by an employer. Essentially, the Workers are not protected by national labor laws; the only rights they have within the platform are those written by AMT itself, which offer only minimal protections for the Workers, ${ }^{28}$ and there is no regulatory governmental body they can appeal to in case of a dispute.

There have been initiatives aimed at expanding the Workers' rights and protections. For example, Turkopticon and TurkerView are platforms intended to balance the rights of AMT Workers with those of Requesters, helping to protect the Workers from being misused or treated unfairly. Turkopticon provides a built-in Requester reputation system, enabling the Workers to quickly identify an unimpeachable client. ${ }^{29}$ TurkerView rates HITs and Requesters according to a number of factors such as hourly wage, work experience, communication, and approval times, helping the Workers to decide whether a particular HIT is worth completing. ${ }^{30}$ Both platforms are indisputably beneficial in overcoming the disadvantaged position of the Workers, but because of the legal protection gap in the jurisdiction system and the disenfranchisement of crowdworkers from labor laws, a space to address actionable and adequate measures has yet to be created.

\section{POOL UNIFORMITY AND WITHDRAWING MONEY}

There is a relative persistency in the claim that AMT offers a diverse pool of workers, ${ }^{31}$ and that it is therefore able to meet the needs of some Requesters who require globally representative samples to complete tasks. At the same time, this pool is generally known to have significant differences from the general public, as well as being geographically homogenous. ${ }^{32}$

Regarding the entire Workers population, it has been found that the AMT Workers in the US are somewhat more educated and younger but with lower income and employment rates than the general public. ${ }^{33}$ Another study appears to reiterate these characteristics through comparison with the American National Election Studies (ANES) sample and elaborates on further defining features. As well as being more educated but less likely to obtain employment than the average population, the Workers are also less religious and more liberal. ${ }^{34} \mathrm{We}$ asked the Workers (sampled globally) what they think about this statement being extrapolated onto a global level, and their opinions varied: $36 \%$ rather agreed with the statements, but often shared the opinion that these characteristics can be mostly explained by age. Young people are more likely to work with 
AMT due to the requirement for computer literacy, are generally less religious, more liberal, and less likely to be employed than the general population.

Despite being advertised as a diverse pool (190 countries), the majority (over 75\%) of AMT's 600k Workers live in the United States and India. ${ }^{35}$ Our sample of Workers confirmed this statement-70.1\% self-reported living in the US and 11.7\% in India. Other countries represented were for example Canada, UK, Italy, and Brazil, all around 3-4\%. Both the demographic and geographic uniformity need not pose an insuperable obstacle for researchers to gain high-quality data from an AMT sample - there has been a growing literature of techniques to achieve this; ${ }^{36}$ the problem here is rather one of the reasons for such uniformity, restricting certain groups of Workers. Explaining the geographic uniformity seems relatively easy. First of all, Amazon is a US-based company and the platform language is English. Secondly, the populations of both India, claiming now to be the second largest English-speaking country in the world, ${ }^{37}$ and US are enormous, ranking respectively second and third in the world. ${ }^{39}$ However, the reason for the pool uniformity is also the partial in/ability of certain groups of Workers to make use of their earnings. ${ }^{40}$ Until very recently, international Workers outside the US and India were not able to deposit their earnings in their local bank accounts. They were only rewarded with Amazon.com gift cards to be used solely on the same, US-based site, ${ }^{40}$ which use would often mean very high delivery fees for foreign Workers. This was, naturally, a disadvantage for international Workers. Not until May 2019 did AMT introduce their collaboration with Hyperwallet, a virtual US bank, which enables the Workers to receive their deposits in their local currency. There are 23 countries included in this scheme, yet for the rest the conditions stay the same. ${ }^{41}$ During our performance, we realized that many Workers are not aware of having such an option, perhaps because this update was publicized only a month earlier:

“... they don't send money directly to Brazil."

"... the money I earn cannot be put into my bank account. I live in the UK and I get paid into the US Amazon site. This is so inconvenient."

After our performance at Art Fair Suomi and almost three months after this update was put into place, one HIT for Workers from outside the US was registered, to find out if they were more familiar with the Hyperwallet option. Taking into account Workers solely from countries included in the scheme, more than a half, 67\%, did not know about this update, and only 33\% were aware. Asking all international Workers, only $28.5 \%$ were familiar with the collaboration as opposed to a vast majority of uninformed Workers, accounting for $71.5 \%$. Furthermore, many Workers aware of the update and coming from countries included in the program reported not being able to use this feature - their account does not show any such option, or they have been informed by AMT that they are not eligible, without further elaboration. Does AMT intentionally disregard some groups of Workers and privilege others? Some level of hierarchal stratification is apparent here, but less apparent are its systemic functioning and eligibility criteria. 


\section{WHY AMT? ARE YOU HAPPY?}

Our aim was also to ascertain the Workers' main motivation for joining AMT. The reason for more than half (62.4\%) of our subjects was "to generate extra income/having not enough money." Other reasons were "for entertainment" (16.2\%), "learning new things/staying productive" (6\%), "in a need of remote work because of disability/injury/other unavoidable circumstances" (5.1\%), "because of its flexibility" (4.3\%), "out of curiosity" (4.3\%), and "to get rid of stress/negative thoughts" $(1.7 \%)$. We also asked the Workers whether they think that this decision was related to the economic and political situation of their country/area. The ratio here was rather similar: $48 \%$ think that it is related to their local political/economic situation, and slightly more, $52 \%$, think that it is not related.

To ascertain the Workers' satisfaction with their employment situation, we tried to draw a link to their current feelings, expanding on the existing correlation found in Owoseni $2015 .^{42}$ The predominant number of the Workers from our sample, $41 \%$, were reportedly feeling sad/bad, $35 \%$ were feeling happy/good, and $24 \%$ were feeling rather neutral. The workers were feeling rather $\mathrm{sad} / \mathrm{bad}$ mainly because of mental health issues, lack of financial means, relationship issues, feeling overworked, feeling frustrated from work, or the inability to find employment. Those who were feeling rather happy/good stated mostly family, upcoming weekend, or small things (for example having a cookie) as their reasons. These findings could be summarized in a statement that a substantial number of the AMT Workers are feeling rather sad and not satisfied with their employment situation. It is from this climate of low wages, scarce worker protections, and prevailing feelings of negativity within the workforce that systemic change should be sought.

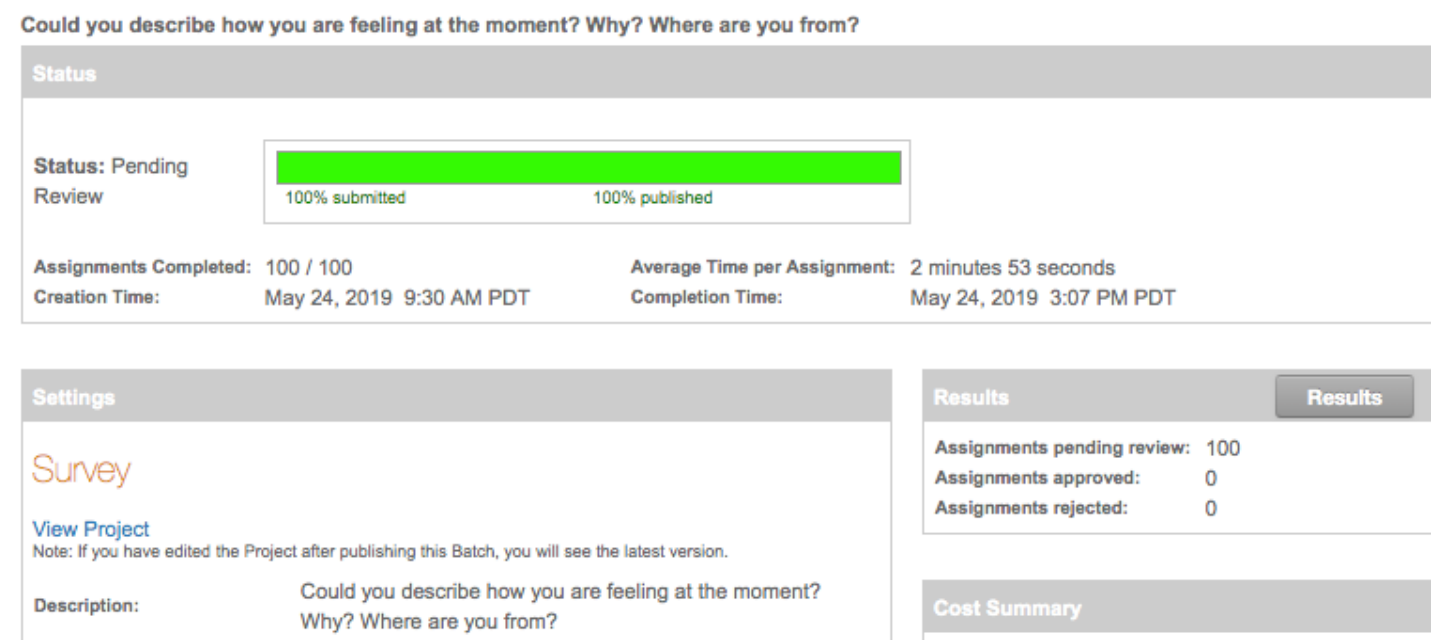

Figure 6. Completed HIT on Amazon Mechanical Turk, 2019, courtesy of the artists 


\section{CONCLUSION}

Our investigative performance project, Shepherd's Office, aimed to present digital labor and its initial problematics to the general public at Art Fair Suomi. Our main objective was to introduce the topic in a cohesive and understandable manner, with the use of art as a means to engage, relate, understand, and reflect. It is worth noting that $S O$ is an ongoing research project and that, at this stage, rather than attempting to reach definite conclusions, it serves as an instigator of a longerterm conversation. Therefore, instead of definite answers, the research pointed out circumstances which need to be reconsidered within AMT policies and regulations, many stemming from the misclassification of the Workers as "freelance contractors" and the general prioritization of Requesters' over Workers' interests: low wages of AMT Workers with no reward for the time "in between," favoring certain groups of Workers, Workers having unequal access to the market and almost no rights within it. Rather than transcending conventional employment models by promising flexible working hours, convenience, and a solution to scarce wages in low-income countries, AMT and the global digital labor market seem to mirror and magnify the issues pertaining to low-wage conventional labor. These circumstances by no means cover all concerns affecting the AMT Workers, but provide an insight into a selection of topics that seem to be currently underrepresented in the equality and regulations discussion. The statistics gained from this research and presented in this paper are not definite for other reasons: they do not represent the entire network of AMT Workers, especially because the research sample was relatively small, and the research outcome is based solely on the Workers' answers, with no way to confirm their validity.

We would like our initiative to contribute to an ongoing conversation among researchers and artists, but also on the level of the general public, which would evolve over time, expand beyond AMT towards wider notions of digital labor and culminate in collectively generated solutions for systemic change. To achieve such a goal, it is necessary to include the microtasking workers themselves in the conversation and hear their full stories rather than drawing solely on constructed statistics, in order to create the right regulations in this vastly unregulated environment and to balance the benefits for Workers and Requesters.

\section{ENDNOTES}

1. Joel Ross, M. Six Silberman, Lilly Iranl, and Andrew Zaldivar,"Who Are the Crowdworkers? Shifting Demographics in Mechanical Turk," Proceedings of the SIGCHI Conference on Human Factors in Computing Systems, Atlanta, GA (April 10-15, 2010): 2864, http://dx.doi.org/10.1145/1753846.1753873.

2. “Overview," Amazon Mechanical Turk, accessed June 20, 2019, https://www.mturk.com/.

3. Winter Mason and Siddharth Suri, "Conducting Behavioral Research on Amazon's Mechanical Turk," Behaviour Research Methods 1, no.44 (March 2012): 1-3, https://doi.org/10.3758/s13428011-0124-6. 
4. Megan Geuss, "Low Pay, Poor Prospects, and Psychological Toll: The Perils Of Microtask Work," Ars Technica, September 23, 2018, https://arstechnica.com/informationtechnology/2018/09/in-most-cases-online-microtask-work-can-be-a-raw-deal-un-study-finds/. 5. Kotaro Hara, Abi Adams, Kristy Milland, Saiph Savage, Chris Callison-Burch, Jeffrey Bigham, "A Data-Driven Analysis of Workers' Earnings on Amazon Mechanical Turk," CHI '18: Proceedings of the 2018 CHI Conference on Human Factors in Computing Systems, Montreal (April 21-26, 2018), Paper No. 449:1-14. Research Collection School of Information Systems. https://doi.org/10.1145/3173574.3174023.

6. Joel Ross, Lilly Irani, M. Six Silberman, Andrew Zaldivar, and Bill Tomlinson, "Who Are the Crowdworkers? Shifting Demographics in Mechanical Turk," Proceedings of the SIGCHI Conference on Human Factors in Computing Systems, Atlanta, GA (April 10-15, 2010): 2865, http://dx.doi.org/10.1145/1753846.1753873.

7. Angela Washko, "SerfNet," accessed September 26, 2019, https://angelawashko.com/section/402501-Serf-Net.html.

8. Aaron Koblin, "The Sheep Market," accessed October 20, 2019, http://www.thesheepmarket.com/.

9. Aaron Koblin, "The Sheep Market: Two Cents Worth,” (Master's Thesis, University of California, Los Angeles, 2006),

http://webcache.googleusercontent.com/search?q=cache:5YOIZ9tO54gJ:www.aaronkoblin.com/ work/thesheepmarket/TheSheepMarket.doc $+\& \mathrm{~cd}=2 \& \mathrm{hl}=\mathrm{cs} \& \mathrm{ct}=\mathrm{clnk} \& \mathrm{gl}=\mathrm{uk}$; Aaron Koblin, "Visualizing Ourselves... with Crowd-Sourced Data," TED: Ideas Worth Spreading. Video File. March 2011, https://www.ted.com/talks/aaron_koblin.

10. Bob Deffinbaugh, "The Good Shepherd and the Flock of God,” Bible.org, May 26, 2004 https://bible.org/seriespage/good-shepherd-and-flock-god.

11. "Home page," The Shepherd's Office, accessed August 15, 2019,

https://theshepherdsoffice.webs.com/.

12. Mark Graham, Isis Hjorth, and Vili Lehdonvirta, "Digital Labour and Development: Impacts of Global Digital Labour Platforms and the Gig Economy on Worker Livelihoods," Transfer: European Review of Labour and Research 23, no. 2 (May 2017): 137, doi: $10.1177 / 1024258916687250$.

13. Mark Graham, Isis Hjorth, and Vili Lehdonvirta, "Digital Labour and Development: Impacts of Global Digital Labour Platforms and the Gig Economy on Worker Livelihoods," Transfer: European Review of Labour and Research 23, no. 2 (May 2017): 137-140, doi: $10.1177 / 1024258916687250$.

14. Kotaro Hara, Abigail Adams, Kristy Milland, Saiph Savage, Chris Callison-Burch, and Jeffrey P. Bigham, “A Data-Driven Analysis of Workers' Earnings on Amazon Mechanical Turk," CHI '18: Proceedings of the 2018 CHI Conference on Human Factors in Computing Systems, Montreal, April 21-26, 2018, Paper No. 449: 1-14, https://doi.org/10.1145/3173574.3174023. 
15. Alana Semuels, "The Internet Is Enabling a New Kind of Poorly Paid Hell," The Atlantic, January 23, 2018, https://www.theatlantic.com/business/archive/2018/01/amazon-mechanicalturk/551192/.

16. Erin Duffin, "State Minimum Wage Rates in the United States as of January 1, 2019, by State (in U.S. Dollars)," Statista, last modified July 29, 2019,

https://www.statista.com/statistics/238997/minimum-wage-by-us-state/.

17. “India Minimum Wage Rate 2019," Minimum-Wage.org, accessed June 18, 2019, https:/www.minimum-wage.org/international/india.

18. Mark Graham, Isis Hjorth, and Vili Lehdonvirta, "Digital Labour and Development: Impacts of Global Digital Labour Platforms and the Gig Economy on Worker Livelihoods," Transfer:

European Review of Labour and Research 23, no. 2 (May 2017): 142,

doi: $10.1177 / 1024258916687250$.

19. “Global Speeds June 2019," Speedtest Global Index, accessed June 20, 2019,

https://www.speedtest.net/global-index.

20. Lilly Irani, "Difference and Dependence among Digital Workers: The Case of Amazon

Mechanical Turk," South Atlantic Quarterly 114, no.1 (January

2015): 226, https://doi.org/10.1215/00382876-2831665.

21. Valerio De Stefano, “The Rise of the 'Just-in-Time Workforce': On-Demand Work, Crowdwork, and Labor Protection in the "Gig Economy," International Labour Office:

Conditions of Work and Employment Series 71, (2016): 1,

https://www.ilo.org/wcmsp5/groups/public/---ed_protect/---protrav/---

travail/documents/publication/wcms_443267.pdf.

22. Valerio De Stefano, "The Rise of the 'Just-in-Time Workforce': On-Demand Work, Crowdwork, and Labor Protection in the "Gig Economy," International Labour Office:

Conditions of Work and Employment Series 71, (2016): 5,

https://www.ilo.org/wcmsp5/groups/public/---ed protect/---protrav/---

travail/documents/publication/wcms 443267.pdf.

23. "Paul Laverty on Sorry We Missed You," Youtube, video, May 21, 2019,

https://www.youtube.com/watch?v=jV6-e04L96s.

24. "Participation Agreement," Amazon Mechanical Turk, last modified December 17, 2018, https://www.mturk.com/participation-agreement.

25. "Workers' Forum," Pilvi Takala, accessed October 20, 2019, https://pilvitakala.com/workersforum.

26. "Business Outsider: Selected Works by Pilvi Takala, Artist-in-Residence in Aalto

University," Aalto University: Showcase, accessed October 20, 2019,

http://showcase.aalto.fi/new-event/pilvi-takala-business-outsider.

27. JC, "How Much Does it Really Cost to Drive Your Car for Uber and Lyft?," Ridester, last modified September 18, 2018, https:/www.ridester.com/uber-lyft-driver-costs-and-expenses/; "Is It Worth Driving for Uber in London? Driver Earning and Money," Uber Driver London, last modified August 23, 2019, https://uberdriverlondon.co.uk/is-it-worth-driving-for-uber-in-london/; 
“Insurance Requirements," Uber Help, accessed October 18, 2019, https:/help.uber.com/partners/article/insurance-requirements?nodeId=72a033a2-de05-4d1f-a23a79bdfb3b14cc.

28. Mark Graham, Isis Hjorth, and Vili Lehdonvirta, "Digital Labour and Development: Impacts of Global Digital Labour Platforms and the Gig Economy on Worker Livelihoods," Transfer: European Review of Labour and Research 23, no. 2 (May 2017): 140, 153, doi:10.1177/1024258916687250; Six Silberman, "Welcome to the Crowd," Red Pepper, December 17, 2018, https://www.redpepper.org.uk/welcome-to-the-crowd/. 29. “About," Turkopticon, accessed September 26, 2019, https://turkopticon.ucsd.edu/. 30. "Find Requesters Worth Working With," TurkerView, accessed October 18, 2019, https://turkerview.com/.

31. Danielle McDuffie, "Using Amazon's Mechanical Turk: Benefits, Drawbacks and Suggestions," Association For Psychological Science, January 30, 2019, https://www.psychologicalscience.org/observer/using-amazons-mechanical-turk-benefitsdrawbacks-and-suggestions; Joseph K. Goodman, Cynthia E. Cryder, and Amar Cheema, "Data Collection in a Flat World: The Strengths and Weaknesses of Mechanical Turk

Samples," Journal of Behavioral Decision Making 26, (2013): 213-224, https://doi.org/10.1002/bdm.1753.

32. Djellel Difallah, Elena Filatova, and Panos Ipeirotis, "Demographics and Dynamics of Mechanical Turk Workers," Proceedings of WSDM 2018: The Eleventh ACM International Conference on Web Search and Data Mining, Los Angeles, (February 5-9, 2018): 3, https://doi.org/10.1145/3159652.3159661.

33. Paul Hitlin, "Research in the Crowdsourcing Age, a Case Study: How Scholars, Companies and Workers Are Using Mechanical Turk, a 'Gig Economy' Platform, for Tasks Computers Can't Handle," Pew Research Centre (July 2016): 20-22,

https://www.pewinternet.org/2016/07/11/research-in-the-crowdsourcing-age-a-case-study/.

34. Kevin E. Levay, Jeremy Freese, and James N. Druckman, "The Demographic and Political Composition of Mechanical Turk Samples," SAGE Open, (January 2016): 13-14, https://doi.org/10.1177/2158244016636433.

35. Djellel Difallah, Elena Filatova, and Panos Ipeirotis, "Demographics and Dynamics of Mechanical Turk Workers," Proceedings of WSDM 2018: The Eleventh ACM International Conference on Web Search and Data Mining, Los Angeles, (February 5-9, 2018): 3, https://doi.org/10.1145/3159652.3159661.

36. Kevin J. Mullinix, Thomas J. Leeper, James N. Druckman, and Jeremy Freese, "The Generalizability of Survey Experiments," Journal of Experimental Political Science 2 (2015): 109-138; Winter Mason and Siddharth Suri, "Conducting Behavioral Research on Amazon's Mechanical Turk," Behaviour Research Methods 1, no.44 (March 2012): 1-23, https://doi.org/10.3758/s13428-011-0124-6.

37. "English Speaking Countries 2019," World Population Review, accessed June 12, 2019, http://worldpopulationreview.com/countries/english-speaking-countries/. 
38. “Total Population by Country 2019”, World Population Review, accessed June 18, 2019, http://worldpopulationreview.com/countries/.

39. Winter Mason and Siddharth Suri, "Conducting Behavioral Research on Amazon's

Mechanical Turk,” Behaviour Research Methods 1, no.44 (March 2012): 1-23, https://doi.org/10.3758/s13428-011-0124-6.

40. Alana Semuels, "The Internet Is Enabling a New Kind of Poorly Paid Hell," The Atlantic, January 23, 2018, https://www.theatlantic.com/business/archive/2018/01/amazon-mechanicalturk/551192/.

41. "Amazon Mechanical Turk Workers in 25 Countries outside of the US Can Now Transfer Their Earnings to Bank Accounts," Amazon Mechanical Turk, last modified May 1, 2019, https://blog.mturk.com/amazon-mechanical-turk-workers-in-23-countries-outside-of-the-us-cannow-transfer-their-earnings-98ec29ef7f7f.

42. Olakitan O. Owoseni, "Employees' Mood and Emotion as Imperatives for Perceived Job Satisfaction," The International Institute for Science, Technology and Education (IISTE) 5, no.5 (2015), https://www.iiste.org/Journals/index.php/IKM/article/view/22293/22798.

\section{AUTHOR BIO}

Zaneta Zukalova is a London-based artist born in Czechia and is one of two members of Shepherd's Office, an investigative performance project that has been held thus far at Tate Modern, London and Art Fair Suomi, Helsinki. Zukalova's personal work uses art as an instrument to highlight environmental and correlated social injustices.

Zukalova has taken part in international art festivals such as Art Fair Suomi 2019, Helsinki, and Pingyao International Photography Festival 2018, China. Her work has been exhibited in independent galleries such as OKNA in Porto, The Tea Building, APT, CGP, Greenwich West and Southwark Platform in London, and SEAS (Socially Engaged Art Salon) in Brighton. She is a cofounder of Decade Zero, an initiative relating climate change to capitalism and social justice. 